\title{
Obligatory inclusion of uncertainty avoids systematic underestimation of Danish pork water use and incentivizes provision of specific inventory data
}

Raffn, Jakob; Hauschild, Michael Zwicky; Dalgaard, Tommy; Djomo, Sylvestre Njakou; Averbuch, Bonnie; Hermansen, John Erik

Published in:

Journal of cleaner production

Link to article, DOI:

10.1016/j.jclepro.2019.06.057

Publication date:

2019

Document Version

Peer reviewed version

Link back to DTU Orbit

Citation (APA):

Raffn, J., Hauschild, M. Z., Dalgaard, T., Djomo, S. N., Averbuch, B., \& Hermansen, J. E. (2019). Obligatory inclusion of uncertainty avoids systematic underestimation of Danish pork water use and incentivizes provision of specific inventory data. Journal of cleaner production, 233, 1355-1365.

https://doi.org/10.1016/j.jclepro.2019.06.057

\section{General rights}

Copyright and moral rights for the publications made accessible in the public portal are retained by the authors and/or other copyright owners and it is a condition of accessing publications that users recognise and abide by the legal requirements associated with these rights.

- Users may download and print one copy of any publication from the public portal for the purpose of private study or research.

- You may not further distribute the material or use it for any profit-making activity or commercial gain

- You may freely distribute the URL identifying the publication in the public portal 
Please cite this article as: Jakob Raffn, Michael Zwicky Hauschild, Tommy Dalgaard, Sylvestre Njakou Djomo, Bonnie Averbuch, John Erik Hermansen (2019) Obligatory inclusion of uncertainty avoids systematic underestimation of Danish pork water use and incentivizes provision of specific inventory data. Journal of Cleaner Production 233, 1355-1365.

\section{Obligatory inclusion of uncertainty avoids} systematic underestimation of Danish pork water use and incentivizes provision of specific inventory data

Jakob Raffn ${ }^{\mathrm{a}, *}$, Michael Zwicky Hauschild ${ }^{\mathrm{b}}$, Tommy Dalgaard ${ }^{\mathrm{a}}$, Sylvestre Njakou Djomo ${ }^{\mathrm{c}}$, Bonnie Averbuch $^{\mathrm{a}}$, John Erik Hermansen ${ }^{\mathrm{a}}$

a Section for Agricultural Systems and Sustainability, Department of Agroecology, Aarhus University, Denmark

b Division for Quantitative Sustainability Assessment, Department of Management Engineering, The Technical University, Denmark

${ }^{\mathrm{c}}$ Ecosys, Institut national de la recherche agronomique (INRA), France

* Corresponding author: E-mail address: raffn@agro.au.dk (Jakob Raffn), Address: Blichers Alle 20, 8830 Tjele, Danmark

Word count ALL: 9896

Word count introduction to references: 7902 


\section{Abstract}

Livestock production is one of the most water-use-intensive economic sectors globally, and pork is the biggest of all meat sectors, necessitating continuous improvement of the sector's water use. Environmental product declarations are one way of incentivizing environmental performance, but with the majority of the water use occurring in primary pig and feed production, methods are required that quantify the water use over the entire value chain. Life Cycle Assessment applies such an approach, and the European Commission's Product Environmental Footprint framework uses this methodology. Product Environmental Footprint studies can use generic data for the pig production and feed cultivation stages and results communicated without uncertainty. Current study aimed to test if using database water footprint inventories could lead to a systematic underestimation of the water use in Danish pork production. A probabilistic surface- and groundwater footprint inventory assessment of the production of $100 \mathrm{~g}$ pork in Denmark was carried out. Danish average industry data was used to assess the possible range of water use for domestic Danish processes and FAOSTAT- and Water Footprint Network data for imported feed. Monte Carlo simulations were used to create water footprint inventory intervals, which were compared with intervals for three inventory databases: EcoInvent, Agribalyse, and Agri-footprint. The water footprint inventory intervals for Danish pork ranged from 3.8 to 9.2 $\mathrm{L} / 100 \mathrm{~g}$ with a coefficient of variation of $21 \%$. Database values were significantly $(\mathrm{p}<0.001)$ left-shifted by 3.0 to $3.9 \mathrm{~L} / 100 \mathrm{~g}$ and 4.4 to $6.6 \mathrm{~L} / 100 \mathrm{~g}$ with significantly different $(\mathrm{p}<0.001)$ coefficients of variation of $6.4 \%$ and $12.3 \%$ for Agri-footprint and Agribalyse respectively. This makes using generic data preferable to using primary data for producers with low water efficiency. Instead of demanding primary data, it is recommended that uncertainties in databases capture the observable variability, and that environmental product declaration results must be communicated with their associated uncertainty. This could incentivize provision of primary data and avoid deliberate underestimations of water use.

Highlights

- Life cycle inventory databases underestimate water use of Danish pork production.

- Product Environmental Footprint allow database values for $>94 \%$ of pork water use.

- Product Environmental Footprints can be published without uncertainty.

- Product Environmental Footprint allow systematic underestimation of water use.

- Databases must capture true values, to incentivize provision of primary data.

Keywords

Life cycle assessment; Agriculture; Uncertainty; Environmental Product Declaration; Water Footprint, Product Environmental Footprint

\section{Introduction}

Freshwater supplies are increasingly strained from consumptive use and pollution (WWAP, 2015). Food production is one of the largest contributors to the exploitation of this resource (Hansen et al., 2017), and meat production accounts for the majority of the sector's water use (Mekonnen and 
Hoekstra, 2012). In Denmark, agriculture is responsible for more than half the country's total direct water use, the majority of which is used for rearing livestock (DST, 2016). Globally, the pig industry is the largest of all the meat sectors, with an annual production exceeding 1.4 billion tons (FAO, 2016), and Denmark follows a similar trend. The Danish pig industry supports a standing population of more than 12 million pigs and piglets, twice the 5.78 million human residents (DST, 2016). This allows for the production of approximately 2 million tons of pork annually. The intensity and scale of pork production necessitates a continued focus on improving efficiency and sustainability of the sector's water use.

One way to stimulate more efficient and sustainable water use is by monitoring, reporting, and verifying it at the product level, as there is a positive correlation between environmental performance and willingness to pay. Additionally, consumers, civil society, and business can make more informed decisions when water use information is communicated through Environmental Production Declarations (EPDs) (EC, 2013). For pork production—and most other livestock products - the majority of water use occurs in the stages prior to the stables and slaughterhouses (de Miguel et al., 2015; González-García et al., 2015), predominantly for irrigating feed crops (Pfister and Bayer, 2014). Consequently, methods that assess the water use over the entire product lifecycle are required to accurately and justly account for the amount of water used to create the final product.

There are two standardized methods to assess water use applying a value chain perspective: the water footprint by The Water Footprint Network (Hoekstra et al., 2011) and the water footprint by ISO (ISO14046, 2014), which builds upon Life Cycle Assessment (LCA) (ISO14044, 2006). Results from studies on value chain water use (i.e. the Water Footprint Inventory (WFI)) vary significantly with values from 1.4 L/100g of Danish pork following the ISO method (TS-RM, 2015) to 23.6 L/100g of pork (Dutch) applying the Water Footprint Network method (Mekonnen and Hoekstra, 2012). While methodological differences exist, such as disagreement on whether a water footprint is volumetric or impact-oriented (Hoekstra, 2016; Pfister et al., 2017), both standards apply bottom-up approaches, and the way water use is accounted for is similar in the two methods (Hoekstra et al., 2011; ISO14044, 2006). Consequently, the difference in results stems from study-specific data-, parameter- and modelling choices. To minimize the effect of unavoidable normative choices, the EC-JRC developed the Product Environmental Footprint guideline (PEF) (EC-JRC, 2013) along with PEF Category Rules (EC, 2016) to harmonize EPDs, and enable a market value for sustainability (EC, 2013). The current paper focuses on issues arising from data use choices.

In LCA, a distinction is made between the specific system under analysis (i.e. the foreground system) and the systems providing inputs to the foreground system (i.e., the background systems). Foreground systems are generally modeled with specific data, while the background system can be modeled with generic data from databases (ISO14044, 2006). It has been shown that WFIs can vary up to an order of magnitude depending on which inventory database is used (Berger and Finkbeiner, 2010). Database values often come from studies at specific sites at specific times and, while inventory studies and 
databases sometimes provide country-specific values or compare one sector to another, they rarely focus on capturing the variability within the sector (Notarnicola et al., 2017). McAuliffe et al. (2018) found significant intra- and inter-farm variation; and generally, agricultural production systems have large spatiotemporal variability due to climatic-, soil-, and management heterogeneity (Notarnicola et al., 2017).

To understand how LCA or water footprint studies on pork production have addressed uncertainty, 49 scientific publications that contained the words "life cycle assessment" OR "water footprint" AND "pork" was identified (See Supplementary Information (SI-A) for details of the evaluation). While roughly two-thirds of the studies addressed uncertainty, 12 studies did not mention or discuss possible implications of uncertainty or variability at all. Roughly half the papers were case studies, of which one-third included water in the inventory $(\mathrm{n}=9)$. Only one study reported the water footprint with quantitative uncertainty, with variance and uncertainty only attributed to the mass of the pigs. About a third of the cases applied Monte Carlo simulations, but less than half of these provided confidence- or prediction intervals, effect sizes, or any other statistical elaboration of their findings. No studies where the variability of the WFI of pork production is evaluated and results communicated with prediction intervals were identified, hence it is not possible to evaluate within which range to expect to find the value chain water use associated with Danish pig production.

Since the early nineties, LCA developers have argued that uncertainty should be quantified and reported in LCA studies (Huijbregts, 1998), yet standardized assessment and reporting of variance and uncertainty was not made a requirement in the PEF Guidelines (EC-JRC, 2013). Instead, the PEF guideline seeks to deal with the variability issue by defining which generic data sources to be used when product specific data is unavailable, and defining when primary data is required and when generic suffices, in product category specific data quality requirements (EC-JRC, 2013). The approved PEF product category rules for feed products require only the feed processing steps modelled with specific data (TS-FP, 2018), even though the majority of water use occur during cultivation of the feed ingredients.

It remains unclear if the water use and uncertainties in generic databases in combination with EPDs being allowed communicated without descriptive statistics makes the use of generic data favorable to providing primary data in pork value chains with inefficient water use. To address this knowledge gap, the current study tested the hypothesis that using database derived water footprint inventory values for pork and feed production could lead to an underestimation of the water use in pork value chains.

\section{Materials and methods}

To test above hypothesis; first, a water footprint inventory assessment of Danish pork was carried out calculating the prediction interval for the water footprint inventory of Danish pork as well as the main feed components. Second, the prediction intervals were compared with values in databases. 


\subsection{Water Footprint Inventory methodology: Danish average pork production case} The case study was carried out with consideration of the ISO14046 Water Footprint Standard (ISO14046, 2014). Following subsections describe the water footprint inventory assessment study design, and are followed by a section describing the inventory analysis.

\subsubsection{Goal and scope of assessment}

The goal was to provide WFI prediction intervals that would capture any Danish pork value chain or production stage thereof and compare these with WFI from the Agri-footprint database (Blonk, 2015b), the Agribalyse database (Koch and Salou, 2016) and the EcoInvent database (Wernet et al., 2016). To enable comparison of the WFI in the current study with the WFI in databases, the methods and modelling approaches were aligned (ISO14044, 2006). Additionally, contribution analyses to estimate the percentage of water use occurring in processes required modelled with primary data in the PEF guidelines was carried out.

Uncertainties can be classified into data-, parameter-, and model uncertainty (Madsen et al., 2010). The water footprint inventory assessment in the current paper addressed data uncertainty only.

The study did not intend to shed light on any environmental impacts, but served solely to test the hypothesis that existing standards and databases in conjunction could lead to a systematic underestimation of water use values, and the strategic communication thereof. The intended audience was academics, politicians and professionals commissioning or carrying out EPDs or making standards governing these.

\subsubsection{Reference flow}

The reference flow ' $100 \mathrm{~g}$ of fresh pork at slaughterhouse exit gate sold for human consumption' was adopted. Moreover, “ 1 ton dry matter animal feed at the animal farm entry gate” was chosen as reference flow for feed production.

\subsubsection{Boundary definitions}

The downstream system boundary was set to the slaughterhouse exit gate (Figure 1). The upstream boundary was set at the cultivation of feed ingredients, in Denmark and abroad. No agricultural processes and inputs apart from irrigation were included. Figure 1 comprise the entire model system, and all processes were modelled as foreground processes with country average data collected accordingly. The WFI assessment focused solely on the volume of surface- and groundwater withdrawn and released in relation to production of the reference flows. Neither water quality parameters nor temporary depletion was included; hence, water withdrawn and released in the same watershed cancelled each other out. 


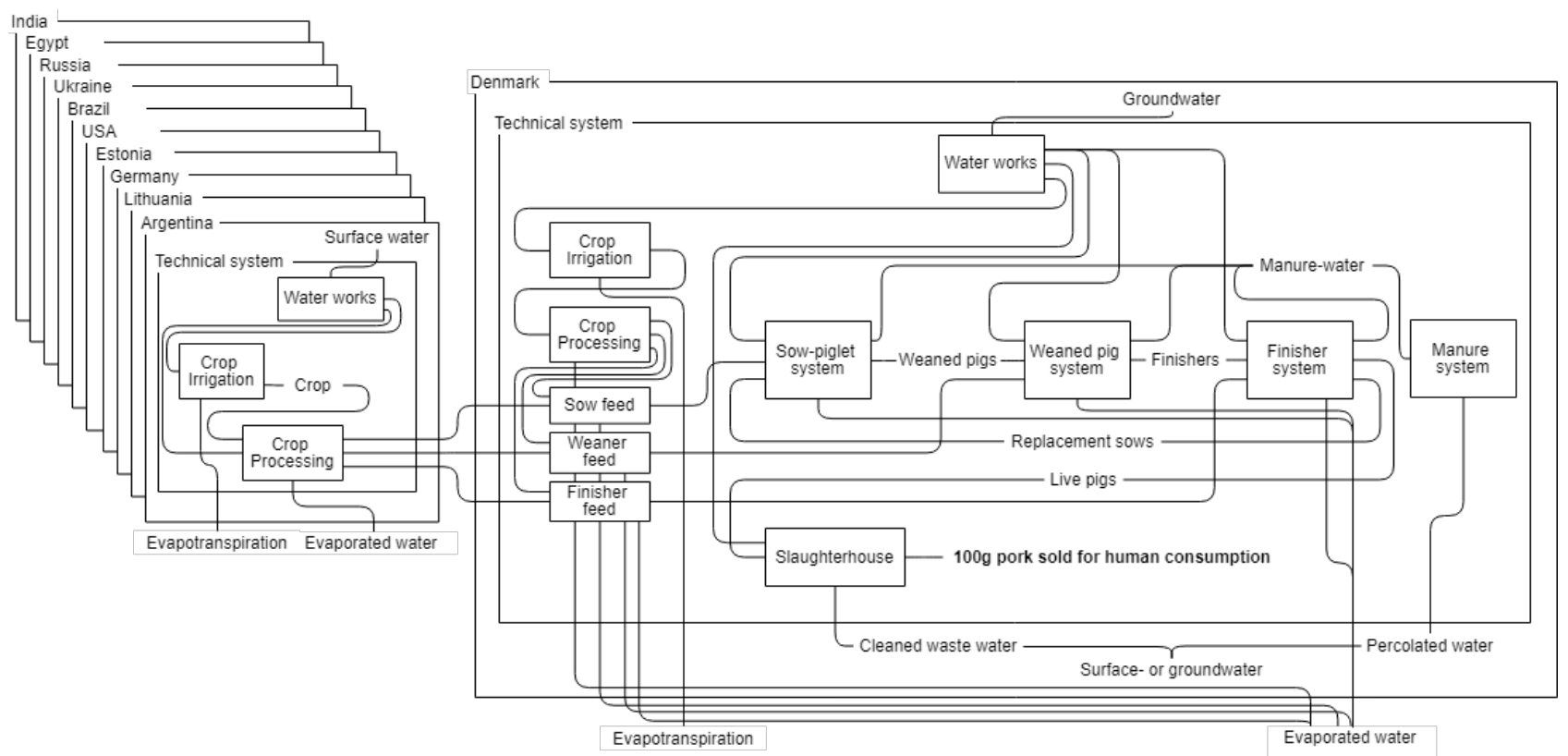

165 Figure 1 Overview of compartments of the water use for pork considered (or modelled).

166

167

168

169

170

171

172

173

174

175

176

177

178

179

180

181

182

183

184

185

\subsubsection{Inventory approach}

To create prediction intervals covering the least and the most water intensive production systems, the approach of a previous study on pork inventories by Basset-Mens and van der Werf (2005), was followed. Minimum values were made the function of favorable conditions, and maximum values the product of unfavorable conditions, while means were the function of all median or mean values (under the assumption of normality). To avoid subsequent citing of uncertain mean values, it was decided that all inventories in the current study should be communicated as 95\% prediction intervals. The details of the inventory analysis can be found in sections 2.2.1 - 2.2.7.

\subsubsection{Multi-functionality and allocation}

Pork value chains are characterized by multi-functionality. Multi-functionality in LCA occur when one process have multiple outputs, and choices will have to be made about how much of each input should be attributed to each output (ISO14044, 2006). Allocation was done according to economic value, following attributional LCA methodology (EC-JRC-IES, 2010). Economic allocation values for plant processing was derived from Mogensen et al. (2018) and meat processing from the PEF Screening Study (TS-RM, 2015). Agribalyse provided only system processes and the documentation file did not provide the specific allocation keys. EcoInvent had no pork production process and was only used for crops which had no allocation between main and by-products. Agri-footprint included such allocation. The current study did not include multi-functionality of crops and allocated $100 \%$ of the water to the grain (see Table 1).

INSERT TABLE 1 HERE 
186 Table 1 Allocation values used in the current study and Agri-footprint and the ratio between the two.

187 No allocation was used for the included unit-processes in EcoInvent, and no information about

188 allocation in Agribalyse could be found

\begin{tabular}{llll}
\hline Product & Current study (\%) & Agri-footprint (\%) & Ratio \\
\hline Crops: & & & \\
Barley grain & 100 & 76.9 & 1.30 \\
Oat grain & 100 & 76.9 & 1.30 \\
Rape seeds & 100 & 100 & 1 \\
Soy beans & 100 & 100 & 1 \\
Sugar beets & 100 & 100 & 1 \\
Sunflower seeds & 100 & 100 & 1 \\
Wheat grain & 100 & 76.9 & 1.30 \\
Processing: & & & \\
Soy-bean meal & 56 & 58.5 & 0.95 \\
Sugar molasses & 5 & 4.3 & 1.16 \\
Rapeseed meal & 24 & 23.9 & 1.01 \\
Sunflower meal & 20 & 20.2 & 0.99 \\
Pork for human consumption & 97.5 & 97.5 & 1.00 \\
\hline
\end{tabular}

189

190

\subsection{Inventory analysis}

$191 \quad 2.2 .1 \quad$ Feed use and feed components

192 The Danish national average feed composition for the pig rearing subsystems Year-sows with suckling 193 pigs, Weaned pigs, and Finishers (DAFC and Vils, 2015) was combined with quartile data on pig feed 194 intake, growth, and mortality obtained from 459 sow farms, 412 weaner farms, and 494 finisher farms 195 in Denmark (Jessen, 2016) (see Table 2 and SI-B). For the feed ingredients potato protein concentrate, 196 oil/fat, amino acids, and minerals were omitted. The total weight of the feed intake per life pig type was 197 calculated by multiplying the feed unit per kilogram growth, the feed weight per feed unit, and the 198 weight increase for each pig type, applying the above-described inventory approach to create intervals.

199 INSERT TABLE 2 HERE

200 Table 2 Estimated feed intake for Year-sows, Weaners and Finishers, average and highest and lowest 201 quartiles.

\begin{tabular}{llll} 
& Year-sow & Weaned pig & Finisher \\
\hline Feed in total, kg, Q25 & 1512 & 43.5 & 216 \\
Feed in total, kg, mean & 1513 & 49.6 & 229 \\
Feed in total, kg, Q75 & 1520 & 56.8 & 245 \\
\hline
\end{tabular}

\section{Feed composition, \%(wet weight)}

Wheat 36

Barley 


\begin{tabular}{llll} 
Soy-bean meal & 7 & 13 & 10 \\
Sunflower meal & 3 & - & 6 \\
Rapeseed cakes & 3 & 2 & 6 \\
Wheat bran/oat & 5 & - & 2 \\
Fish meal & - & 2 & - \\
Potato concentrate & - & 5 & - \\
Oil/fat & 1.5 & 3 & 1 \\
Molasses from sugar beets & 1.2 & 1 & 1 \\
Amino acids & 0.5 & 1 & 1 \\
Minerals & 2.8 & 3 & 2 \\
\hline
\end{tabular}

202

203

204

205

206

207

208

209

210

211

212

213

214

215

216

217

218

219

220

221

222

223

224

225

226

227

228

\subsubsection{Feed origin}

The origin of each feed ingredient was calculated based on data from the Danish National Statistics Office (DST, 2016) and FAO (FAO, 2016) and values can be found in the report from Aarhus University (Mogensen et al., 2017) (see Table 3 for import percentages). The method applied identified the countries from which crops were imported, then the import-export mix for these countries were assessed. It is a matrix based approach with a cut-off at third tier importer. Overall, there was a balance between cereal and rapeseed production and their use in Denmark (DST, 2016). Thus, all cereals and rapeseed cakes were assumed to have been produced in Denmark. Soybean meal was estimated to be produced in and imported from Argentina (64\%), Brazil (28\%) and the USA (8\%). Sunflower meals were estimated to have been produced in and imported from Russia (40\%), Ukraine (35\%), Estonia (14\%), Germany (5\%) and Lithuania (6\%). Sugar beet molasses were estimated to originate from India (36\%), Russia (34\%), Ukraine (16\%), Denmark (10\%) and Egypt (4\%) (FAO, 2016). Only mean values for the import mix were available and no parameterization was carried out to evaluate the variability induced by shifting import patterns.

\subsubsection{Water use in feed production}

As data availability and quality on irrigation differ between domestic and imported crops, different methods were applied to assess water use of domestic and imported feed constituents (see SI-C).

\subsubsection{Water use in domestically cultivated feed}

Two approaches were applied to determine the Danish irrigation coverage. The first approach analyzed data from the MarkID database covering all field in Denmark (Jørgensen et al., 2015). Irrigation permits are provided at farm level, and the irrigated area was extracted for cereals on sandy soils using ArcGIS and R-Studio 1.1.383. The assumption of limiting the search to the subset of sandy soils (i.e., with $>65 \%$ (w) sand particles $0.002-2 \mathrm{~mm}$ and $0-10 \%$ (w) clay particles $<0.002 \mathrm{~mm}$ (following the international soil classification)) was made because other soil types in Denmark are primarily irrigated for the cultivation of vegetables. The second approach was based on a dataset including data from 9,000 Danish farms, collected between 2007 and 2011, containing the area under irrigation as well as 
farm type. Cattle farms were excluded as they were assumed to produce feed only for their own herds, 230 resulting in a subset of pig- and plant cultivation farms. The irrigation coverage was estimated to be $23111 \%$ and $12 \%$ for the first and second approaches, respectively, and a mean value of $11.5 \%$ was 232 applied. The dataset provided farm level permits, and to translate this into water use, the utilization 233 degree of irrigation permits was calculated. From the Jupiter database on water withdrawal in Denmark 234 (GEUS, 2017), the actual withdrawn water was divided by the permitted withdrawal for each Danish 235 irrigation well and averaged. From 2010 to 2016, 45\% of the allowed irrigation water was utilized at 236 the national level. The utilized fraction varies significantly between regions and lower and upper bounds were defined to $30 \%$ and $60 \%$ respectively. The irrigation coverage and degree of utilization was multiplied with Danish national recommendations for irrigation amounts per crop type obtained from Hvid (2011), where data is based on water deficit calculations by the Danish Meteorological Institute. A sample period from 2001 to 2010 was chosen, as these data are more representative for moisture deficits than earlier periods (Refsgaard et al., 2011). The lowest and highest moisture deficit was applied to define lower and upper bounds, respectively. All irrigated water was assumed to be evapotranspired, as farmers only irrigate when needed due to cost optimization. The water footprint inventory for irrigation was calculated for two scenarios; 1) All Danish feed crops irrigated according to moisture deficit (FULL), and 2) Best estimate of mean irrigation, as described above. The full irrigation scenario was used to assess the potential upper limit for water withdrawal for crop production, and the mean irrigation scenario was the best estimate of the likely prediction interval for the functional unit for meat and the reference flow for feed.

INSERT Table 3 HERE

Table 3 The origin and import mix along with mean, upper and lower bounds for estimated annual irrigation for each crop type used in pig feeds in Denmark.

\begin{tabular}{|c|c|c|c|c|c|c|c|c|}
\hline \multirow[b]{2}{*}{ Crop } & \multirow{2}{*}{$\begin{array}{l}\text { Country of } \\
\text { origin }\end{array}$} & \multirow{2}{*}{$\begin{array}{l}\text { Contribution } \\
\%\end{array}$} & \multicolumn{3}{|c|}{ Irrigation $\left[\mathrm{m}^{3} / \mathrm{ha}\right]$} & \multicolumn{3}{|c|}{ Moisture deficit $\left[\mathrm{m}^{3} / \mathrm{ha}\right]$} \\
\hline & & & Min & Mean & Max & Min & Mean & $\max$ \\
\hline Barley or oats ${ }^{\text {a) }}$ & Denmark & 100 & 72 & 549 & 1449 & 210 & 1061 & 2100 \\
\hline \multirow[t]{5}{*}{ Sugar beets } & Denmark & 10 & 104 & 362 & 725 & 100 & 700 & 1050 \\
\hline & Egypt & 4 & 8400 & 9200 & 10400 & & & \\
\hline & India & 36 & 0 & 0 & 0 & & & \\
\hline & Russia & 34 & 3 & 585 & 2812 & & & \\
\hline & Ukraine & 16 & 4 & 140 & 575 & & & \\
\hline Rape-seeds & Denmark & 100 & 128 & 655 & 1608 & 370 & 1270 & 2330 \\
\hline \multirow[t]{3}{*}{ Soy beans } & Argentina & 64 & 0.4 & 33 & 322 & & & \\
\hline & Brazil & 28 & 0.01 & 2 & 8 & & & \\
\hline & USA & 8 & 0.01 & 299 & 2457 & & & \\
\hline
\end{tabular}




\begin{tabular}{lllllllll}
\hline Sunflower seeds & Estonia & 14 & 0 & 0 & 0 & & & \\
& Germany & 5 & 0 & 0 & 0 & & & \\
& Lithuania & 4 & 0 & 0 & 0 & & & \\
& Russia & 42 & 0.1 & 13 & 133 & & & \\
Wheat & Ukraine & 35 & 0.1 & 35 & 148 & & & \\
& Denmark & 100 & 159 & 727 & 1697 & 460 & 1400 & 2460 \\
\hline
\end{tabular}

a) There was no moisture deficit data for oats available, so values for barley were applied instead.

252

253

254

255

256

257

258

259

260

261

262

263

264

265

266

267

268

269

270

271

272

273

274

275

276

277

278

279

\subsubsection{Water use in feed cultivated abroad}

Surface and groundwater use values (blue water) were derived from Mekonnen and Hoekstra (2011) and calculated $\mathrm{WFI}_{\min }, \mathrm{WFI}_{\text {mean }}$ and $\mathrm{WFI}_{\max }$ values by multiplying the WFI in the county with the lowest, average, and highest surface- and groundwater footprint, with the lowest, average, and best yield, for the period 2010-2014 obtained from FAOSTAT (2016). The WFI of palm oil was omitted, as the surface and groundwater use values in Mekonnen and Hoekstra (2011) were 0 and in Siebert and Döll $(2010)<0.5 \mathrm{~m}^{3} /$ ton and the fraction of oil in the feed used for pork production is minimal.

\subsubsection{Water use in the stables}

Two approaches for assessing the water use in stables for drinking and cleaning were used to assess withdrawal and release factors.

The first approach utilized the water to feed ratio of $3 \mathrm{~L}$ of water per $1 \mathrm{~kg}$ of feed, with a minimum value of 2:1 and a maximum value of 5:1 (Schiavon and Emmans, 2000). The rates were multiplied by the feed intake calculated earlier, with identical fate modeling. The second approach was based on pig residency times and the average amount of water a pig drinks and excretes per day, according to pig category (Pig time) (see SI-D). The water use in the stables was calculated per year-sow and for the number of weaned piglets and finishers per year sow (see Table 5). The format was chosen for methodological transparency and ease of repeatability as well as to enable data inclusion in subsequent studies.

Data was compiled from eight studies reporting pig drinking water use in a comparable way (Andersen, 1985; Larsson, 1997; Li et al., 2005; Magowan et al., 2007; Phillips et al., 1990; Predicala et al., 2013; Tavares et al., 2014; Torrey et al., 2008), and used this to identify min, mean and max values. Data on pig rearing time and weight, and data on spatial requirements was obtained from Jessen (2016) and SEGES (2016a). Pig physiology data was obtained from Schiavon and Emmans (2000). Several studies of pork production have measured pig water use (e.g., Gutiérrez et al. 2016), but only one study reporting the water use specifically for cleaning of pens (Predicala et al., 2013) was identified and included in the current study. The pigs were assumed moved twice prior to transport to the slaughterhouse (when weaned and when moved into the finisher pens) and cleaning taking place after 
moving. Equations 1 - 4 were used to estimate the water withdrawn and released for each pig type and the parameters used shown in Table 4.

$$
\begin{aligned}
& \text { Finisher }_{\text {water use, } \min }=a_{\text {min }} \times c_{\text {min }} \times e_{\text {min }}+h \times k_{\text {min }} \\
& \text { Finisher }_{\text {water intake, } \min }=\text { Finisher }_{\text {water }} \text { use, } \min \times(1-q) \\
& \text { Finisher }_{\text {water to air, } \min }=\text { Finisher }_{\text {water intake, } \min } \times p+0.05 \times h \times k_{\text {min }} \\
& \text { Finisher } \text { water to manure, } \min =\text { Finisher }_{\text {water use, }} \text { min }- \text { Finisher }_{\text {water to air, } \min }-a_{\min } \times l \times n
\end{aligned}
$$

282

283

284

285

286

287

288

289

290

291

292

293

294

To estimate the total water use, for each animal category drinking water use was multiplied with the number of pigs produced by one year-sow and with the rearing time (see equation 1 , calculating the Finisher min. water use). The cleaning water use per pig was estimated by multiplying water use per square meter with the minimum Danish legal area requirement for each pig category. Evaporated water was estimated by subtracting the percentage of direct wastage of water from the total water use and multiplied with the fraction of water evaporated. Additionally, it was assumed that $5 \%$ of the water used for cleaning dissipated as mist through the ventilation system (see equation 2 and 3) while the rest ended up in the manure. The water that wasnt't embedded in the animals (70\% of the live weight) or evaporated ended up in the manure (equation 4). Manure-water was assumed returned to the same watershed through the field application, as irrigation or soil water cover evapotranspiration. Hence,

\begin{tabular}{|c|c|c|c|c|c|c|}
\hline ID & Parameter [unit] & $\mathrm{n}(\mathrm{obs})$ & Min & Mean & Max & References \\
\hline$a$ & Finisher per year sow [No. of pigs] & $459^{b)}$ & 28.15 & 30.85 & 32.85 & See SI-B \\
\hline$b$ & $\begin{array}{l}\text { Weaned pigs per year sow [No. of } \\
\text { pigs] }\end{array}$ & $459^{b)}$ & 29.20 & 31.80 & 33.80 & (Jessen, 2016) \\
\hline$C$ & Finisher rearing time [days] & $480^{b)}$ & 75.50 & 90.75 & 106 & (Jessen, 2016) \\
\hline$d$ & Weaned pigs rearing time [days] & $404^{\mathrm{b})}$ & 45.50 & 49 & 52.50 & (Jessen, 2016) \\
\hline$e$ & Finisher water use [L/(pig*day)] & $\begin{array}{l}53992 \\
\text { c) }\end{array}$ & 5.26 & 7.44 & 9.68 & (See SI-D) \\
\hline$f$ & Weaned pigs water use [L/(pig*day)] & $1440^{c)}$ & 1.02 & 2.76 & 4.79 & (See SI-D) \\
\hline$g$ & Year sow water use [L/(pig*day)] & $144^{\mathrm{c})}$ & 9.30 & 19.25 & 37.90 & (See SI-D) \\
\hline$h$ & Area required for one finisher $\left[\mathrm{m}^{2}\right]$ & - & - & 0.65 & - & (SEGES, 2016b) \\
\hline$i$ & Area required for one weaned pig $\left[\mathrm{m}^{2}\right]$ & - & - & 0.30 & - & (SEGES, 2016b) \\
\hline$j$ & Area required for sow-year $\left[\mathrm{m}^{2}\right]^{\mathrm{a})}$ & - & - & 8.12 & - & (SEGES, 2016b) \\
\hline$k$ & Average cleaning water use $\left[\mathrm{L} / \mathrm{m}^{2}\right]$ & $336^{c)}$ & 22.90 & 28.90 & 34.90 & $\begin{array}{l}\text { (Predicala et al., } \\
\text { 2013) }\end{array}$ \\
\hline$l$ & Finisher weight $[\mathrm{kg}]$ & $480^{b)}$ & - & 110 & - & (Jessen, 2016) \\
\hline$m$ & Weaned pigs weight [kg] & $404^{\mathrm{b})}$ & - & 30 & - & (Jessen, 2016) \\
\hline
\end{tabular}
manure-water was only temporally displaced which does not count as consumptive water use.

\section{INSERT Table 4 HERE}

Table 4 List of parameters used to estimate the water use and the fate in the stable 
$n \quad$ Water content in pigs [\%]

$p \quad$ Water evaporated [\%]

$q \quad$ Finisher direct water waste [\%]

$r \quad$ Weaned pigs direct water waste [\%]

$s \quad$ Sow direct water waste [\%]

$\begin{array}{llll}- & - & 70 & - \\ 150^{c)} & - & 29.53 & - \\ - & - & 31 & - \\ - & - & 31 & - \\ - & - & 40 & -\end{array}$

(Schiavon and

Emmans, 2000

(Schiavon and

Emmans, 2000)

(See SI-D)

(See SI-D)

(See SI-D)
303

304

305

306

307

308

309

310

311

312

313

314

a) Sum of the legal area required for farrowing and gestating sows multiplied with litters per year

b) Number of farms

c) Number of animals

INSERT Table 5 HERE

Table 5 Estimated drinking and cleaning water used in the stable (mean, minimum and maximum) for each stage of pig rearing and the amount that ended up in manure and was evaporated, respectively, for each of two estimation methods. All values were related to the number of pigs produced per year sow, which are provided in the first column.

\begin{tabular}{|c|c|c|c|c|c|c|c|c|c|c|}
\hline \multirow{2}{*}{$\begin{array}{l}\text { Category \& } \\
\text { number }\end{array}$} & \multirow{2}{*}{$\begin{array}{l}\text { Estimation } \\
\text { method }\end{array}$} & \multicolumn{3}{|c|}{ Water used [L] } & \multicolumn{3}{|c|}{ Water to manure [L] } & \multicolumn{3}{|c|}{ Water to air [L] } \\
\hline & & $\min$ & mean & $\max$ & $\min$ & mean & $\max$ & $\min$ & mean & $\max$ \\
\hline Year-sow & Pig time & 3581 & 7259 & 14116 & 2610 & 5595 & 11194 & 613 & 1259 & 2471 \\
\hline 1 & Water:Feed & 3025 & 4539 & 7601 & 1875 & 2859 & 4864 & 862 & 1339 & 2318 \\
\hline Weaned & Pig time & 1467 & 4311 & 8510 & 547 & 2751 & 6045 & 300 & 883 & 1745 \\
\hline $\begin{array}{l}31.8 \\
29.2-33.8\end{array}$ & Water:Feed & 2764 & 4733 & 9037 & 1714 & 2982 & 5783 & 788 & 1396 & 2756 \\
\hline Finishers & Pig time & 13452 & 20843 & 33733 & 8168 & 14205 & 24671 & 2740 & 4246 & 6872 \\
\hline $\begin{array}{l}30.8 \\
28.1-32.9\end{array}$ & Water:Feed & 13346 & 21185 & 37725 & 8275 & 13347 & 24144 & 3804 & 6250 & 11506 \\
\hline
\end{tabular}

\subsubsection{Water use at slaughterhouse}

Data on water use was obtained for six of Danish Crown's (the largest meat processor in Denmark) slaughterhouses in Denmark for the years 2014-15 and 2015-16 (see SI-E). The six slaughterhouses account for approximately $80 \%$ of the Danish pork production (DST, 2016). Min, mean and max water use values were calculated for each of the six slaughterhouses. The processing of pork requires with 95\% confidence between 0.158 and $0.25 \mathrm{~L} / 100 \mathrm{~g}$ surface- and groundwater, with $91 \%$ - 99\% being sent to treatment as wastewater and discharged to surface waters.

\subsubsection{Comparison of calculated WFI with WFIs from LCI databases.}

To test the hypothesis stated in the goal formulation, the prediction intervals of WFI was compared with the WFI prediction intervals in the LCI databases EcoInvent- (Wernet et al., 2016), Agri-footprint(Blonk, 2015a, b), and Agribalyse (Koch and Salou, 2015). 
Agri-footprint contained uncertainty information on $1.1 \%$ of the processes related to the production of pork for human consumption (Blonk, 2015b). There was no variability of the slaughterhouse processes, modeled as a foreground system. The animal rearing stage had the weight of the pigs parameterized, while feed manufacturing, the consumption mix, drying, and processing contained no variability. For crop cultivation, the yield and the straw to grain ratio was parameterized. There was no uncertainty information on water-related elementary flows in any of the stages. Agribalyse provided variability for 63 percent of all processes related to the production of pork for human consumption and the coefficient of variations ranged from $2 \%$ to $20 \%$ for freshwater elementary flows, with all but one being above $10 \%$. The variability and uncertainty in the Agribalyse and Ecoinvent was assessed through expert judgment using a pedigree-matrix approach (see Ciroth et al., 2016 for elaboration on the method), where qualitative parameters such as temporal and spatial representativeness determine the standard deviation of the mean, with the actual variability remaining unknown.

The geographical coverage of the three evaluated databases differed: while EcoInvent and Agribalyse contain no values specific for Denmark, Agri-footprint had WFIs for Danish cereals. Therefore, to compare database values with the WFIs obtained in the current study, unit processes for European countries between the $45^{\text {th }}$ and $60^{\text {th }}$ northern latitude, were merged into joined processes. For example, EcoInvent had no rape seed LCIs for Denmark, and hence rape seed production processes for Germany (2), France (1) and Switzerland (3) were merged into one process, and the prediction interval for the merged process was assessed. For imported crops the import mix was mimicked to the extent that the values were available, such as soy beans in Agri-footprint, but for EcoInvent only soy bean processes for Switzerland were available. Agribalyse provided only one process for wheat and one for sugar beets, and had no LCIs for soy, sunflower, or rape seed, and the barley LCI contained no irrigation water.

\subsubsection{Data analysis and calculations}

Data preprocessing was done in MS Excel 2016 and R Studio Version 1.1.383.

The calculated minimum, mean and maximum values were manually entered into the LCA modelling software SimaPro 8.5.0.0 and a triangular distribution was applied. Following the standard definition, of the triangular distribution the minimum value was the lower bound of the probability density function, the mean was the mode and the maximum was the upper bound of the probability density function. Monte Carlo simulations were carried out with 1,000 iterations to enable bootstrapping of probability density functions and the individual simulation runs exported as a txt-file. The seed-value used in SimaPro's Monte Carlo random number generator was set to 1234, ensuring full repeatability. Statistical analysis of the model runs was done in R Studio (see SI-F for R scripts and SI-G for model runs). The distributions were visually evaluated for normality with histograms and qqplots. Fisher's test and Wilcoxon-Mann-Whitney rank-sum test were carried out to test if the distributions were significantly different from each other.

To enable statistical contribution analysis, the inventory model was designed so that the production stages: feed cultivation, stable and slaughtering were assigned with the respective elementary flows, 
irrigation, well and lake in SimaPro. The same approach was applied to the database processes from EcoInvent, Agri-footprint and Agribalyse databases where new test unit processes were defined and only surface- and groundwater flows included. An R function was designed that grouped and summed all water flows according to production stages for each model run. The contribution of the WFI for each stage to the overall WFI was calculated as a percentage for each model run. Prediction intervals for both the WFI and the contribution of each production stage were calculated under the assumption of normality using the student's t-distribution. To further evaluate the robustness of the contribution analysis, a pairwise evaluation of the WFI for each stage, was done for each Monte Carlo simulation iteration, resulting in frequencies for $\mathrm{WFI}_{\text {slaughter }}>\mathrm{WFI}_{\text {stable }}>\mathrm{WFI}_{\mathrm{Feed}}$.

The effect of using database WFI values instead of values specific to the Danish context was assessed. EcoInvent had no process for pork meat at slaughterhouse exit gate, and hence the effect size for the reference flow for meat was only estimated for Agri-footprint and Agribalyse. Effect sizes for the reference flows for feed were estimated for all databases. The effect size was calculated as the difference between each production stage for each study for each model run, following the same procedure for grouping as described above. The WFI was subtracted by the WFI of Agri-footprint and Agribalyse. The mean difference as well as the prediction interval of the differences were calculated and reported.

To evaluate the difference in variability induced by using secondary instead of primary data, coefficients of variations were calculated for both reference flows for each of the production stages in the current study and in the three databases.

\section{Results}

\subsection{Water footprint inventory of feed}

The WFI attributable to feed cultivation and processing was with 95\% confidence between 3.1 and 8.3 $\mathrm{L} / 100 \mathrm{~g}$ pork at the slaughterhouse exit gate. The difference between the findings and the WFI in Agrifootprint was 1.8 to $7.1 \mathrm{~L} / 100 \mathrm{~g}$. The difference from Agribalyse was -1.2 to $4.4 \mathrm{~L} / 100 \mathrm{~g}$, and hence included zero. The Wilcoxon rank sum test revealed a significant $(\mathrm{p}<0.001)$ left shift of the WFI values for both databases. The effect of using database values was much greater when it was assumed that a sampled Danish farm irrigate all feed crops according to moisture deficit. In this scenario, the WFIs would with $95 \%$ confidence be underestimated with 33 to $94 \mathrm{~L} / 100 \mathrm{~g}$ and 31 to $92 \mathrm{~L} / 100 \mathrm{~g}$ if Agri-footprint and Agribalyse were used respectively.

The estimated WFIs were significantly higher in the current study than in any of the databases for all crops, with the exception of sunflower seeds, where the prediction intervals overlapped for Agrifootprint, Agribalyse and the current study (Table 6). However, the upper bound of the 95\% prediction interval in the current study exceeded the upper bound of Agri-footprint, with $17 \mathrm{~m}^{3} / \mathrm{ton}$. The maximum WFI estimated for wheat cultivation, if farmers irrigated according to the moisture deficit $\left(490 \mathrm{~m}^{3} / \mathrm{ton}\right)$, which is the case on many sandy soils in Denmark, exceeded the maximum value in Agri- 
footprint ( $5 \mathrm{~m}^{3} / \mathrm{ton}$ ) by more than 90 times (see Table 6). The $95 \%$ prediction interval of the difference 390 between the full irrigation scenario and Agri-footprint was $88-454 \mathrm{~m}^{3} / \mathrm{ton}$. This difference was even 391 greater when the results were compared to EcoInvent and Agribalyse.

392 The WFIs of the crops in the current study were characterized by high variability with coefficients of 393 variation for all crops but sugar beets exceeding 40\%. For comparison, the coefficient of variation for 394 WFI for cereals in Agri-footprint was around 5\%, in EcoInvent between 7\% and 11\%. The coefficients 395 of variation in Agribalyse ranged from 0\% to 46\% (Table 7). The distributions were generally slightly 396 left-skewed, albeit not approaching log-normal. The skewness in the current study was an effect of the 397 choice of triangular distribution, where the mean values was closer to the minimum than the maximum 398 value, creating a tailing effect (see description of the distribution above).

399 INSERT TABLE 6 HERE

400 Table 6 Water used for irrigation of crops from LCI databases and the current study expressed as 95\% 401 prediction intervals. The number of countries included is shown in parentheses.

\begin{tabular}{|c|c|c|c|c|c|}
\hline & \multicolumn{3}{|c|}{ Inventory databases $\left[\mathrm{m}^{3} / \text { ton }\right]^{\mathrm{a})}$} & \multicolumn{2}{|c|}{ Current study [m³/ton] ${ }^{\mathrm{a})}$} \\
\hline & Agri-footprint & EcoInvent 3 & Agribalyse & Best estimate & Full irrigation \\
\hline Barley & $0.21-0.23(1)^{b)}$ & $0.97-1.4(1)^{c)}$ & $0(2)^{c)}$ & $4.0-26$ (1) & $76-380(1)$ \\
\hline Oat & $0.13-0.14(1)^{b)}$ & - & - & 5.0-31 (1) & $93-460(1)$ \\
\hline Rapeseed & $0.16-0.18(1)^{b)}$ & $2.4-3.4(6)^{c)}$ & $2.7-5.4(2)^{\mathrm{c})}$ & $9.5-58(1)$ & $200-900(1)$ \\
\hline Soy-beans & $13-29(3)^{b)}$ & $1.2-1.7(2)^{c)}$ & - & $17-120(3)^{b)}$ & - \\
\hline Sugar beets & $1.7-2.1(2)^{c)}$ & 0.07-0.09(1) ${ }^{\mathrm{c})}$ & $1.4-1.6(1)^{c)}$ & $11-32(5)^{b)}$ & $12-33(5)$ \\
\hline Sunflower seeds & $8.2-34(5)^{b)}$ & $1.6-2.3(1)^{\mathrm{c})}$ & $17-35(1)^{c,)}$ & $9.4-51(5)^{b)}$ & - \\
\hline Wheat & $4.6-5.4(1)^{b)}$ & $1.1-1.6(4)^{c)}$ & $3.0-3.6(3)^{c)}$ & 3.7-31 (1) & $120-490(1)$ \\
\hline Finisher feed & $4.1-4.1(1)^{c)}$ & - & $11.5(1)$ & $10-35(1)$ & $120-270(1)$ \\
\hline
\end{tabular}

a) The reference flow for feed

b) Danish crops or exact import mix

c) Based on available non-Danish database processes for North European countries

402

INSERT Table 7 HERE

404 Table 7 Coefficients of variation for the modeled crops. Missing values was due to the crop not being 405 present in the database

\begin{tabular}{lllll}
\hline Crop & $\begin{array}{l}\text { Agri-footprint } \\
{[\%]}\end{array}$ & $\begin{array}{l}\text { EcoInvent } \\
{[\%]}\end{array}$ & $\begin{array}{l}\text { Agribalyse } \\
{[\%]}\end{array}$ & $\begin{array}{l}\text { Current study Best Est. } \\
{[\%]}\end{array}$ \\
\hline Barley & 0 & 8 & 0 & 43 \\
Oat & 0 & - & - & 42 \\
Rapeseed & 6 & 11 & 45 & 43 \\
\hline
\end{tabular}




\begin{tabular}{lllll}
\hline Soy-beans & 35 & 7 & - & 47 \\
Sugar beets & 6 & 0 & 0 & 29 \\
Sunflower seeds & 7 & 11 & 17 & 41 \\
Wheat & 4 & 8 & 6 & 42 \\
Compound feed & 0 & - & 0 & 21 \\
\hline
\end{tabular}

406

407

408

409

410

411

412

413

414

415

416

417

418

419

420

421

422

423

424

425

426

427

428

429

\subsection{Stable}

During the animal rearing stage, between $0.08 \mathrm{l}$ and $1.06 \mathrm{~L}$ of surface- and groundwater was removed from the watershed to produce $100 \mathrm{~g}$ of pork for human consumption. Substantially more was temporally removed $(\sim 0.6 \mathrm{l}-2.3 \mathrm{l})$ but returned in the form of manure. These prediction intervals were comparable to those of Agri-footprint 1.6-2.1 L/100g and Agribalyse 0.7- $1.6 \mathrm{~L} / 100 \mathrm{~g}$, albeit with a higher spread of values. 0.01 to $0.02 \mathrm{~L} / 100 \mathrm{~g}$ of pork was used for cleaning, of which $95 \%$ percent was returned to the same watershed, making the contribution negligible.

\subsection{The total Water Footprint Inventory}

The best estimate of the prediction interval of the WFI for pork produced in Denmark was, with a 95\% confidence, 3.8- 9.2 L/100g (Table 8). The contribution analysis revealed that the feed stage contributed $78-96 \%$ or 3.0-8.3 L/100g to the total water use, the animal rearing stage accounted for 2$16 \%$ or $0.1-1.0 \mathrm{~L} / 100 \mathrm{~g}$, and the slaughtering processes contributed $2-6 \%$ or $0.25-0.27 \mathrm{~L} / 100 \mathrm{~g}$. Onethird of the feed related WFI could be attributed to imported crops and two-thirds to crop cultivation in Denmark. This contribution pattern was similar to the pattern observed in Agribalyse, while Agrifootprint had equal contributions from feed and stable (Table 8). As the probability density functions were not fully normally distributed, the robustness of the findings were evaluated with a pairwise comparison. Despite the large variation of each stage and the apparently large overlaps (Figure 2), the pairwise analysis showed that only in $2.3 \%$ of the model runs did the stable WFI exceed the WFI of imported feed, which in turn only exceeded the WFI of the domestic feed in $6.1 \%$ of the model runs. The WFI of the slaughterhouse, while situated inside the probability density functions for the stable only exceeded the water use in stables in $8 \%$ of the simulations, underpinning that it was the least significant of the production stages in regards to quantitative water use.

INSERT FIGURE 2 HERE 


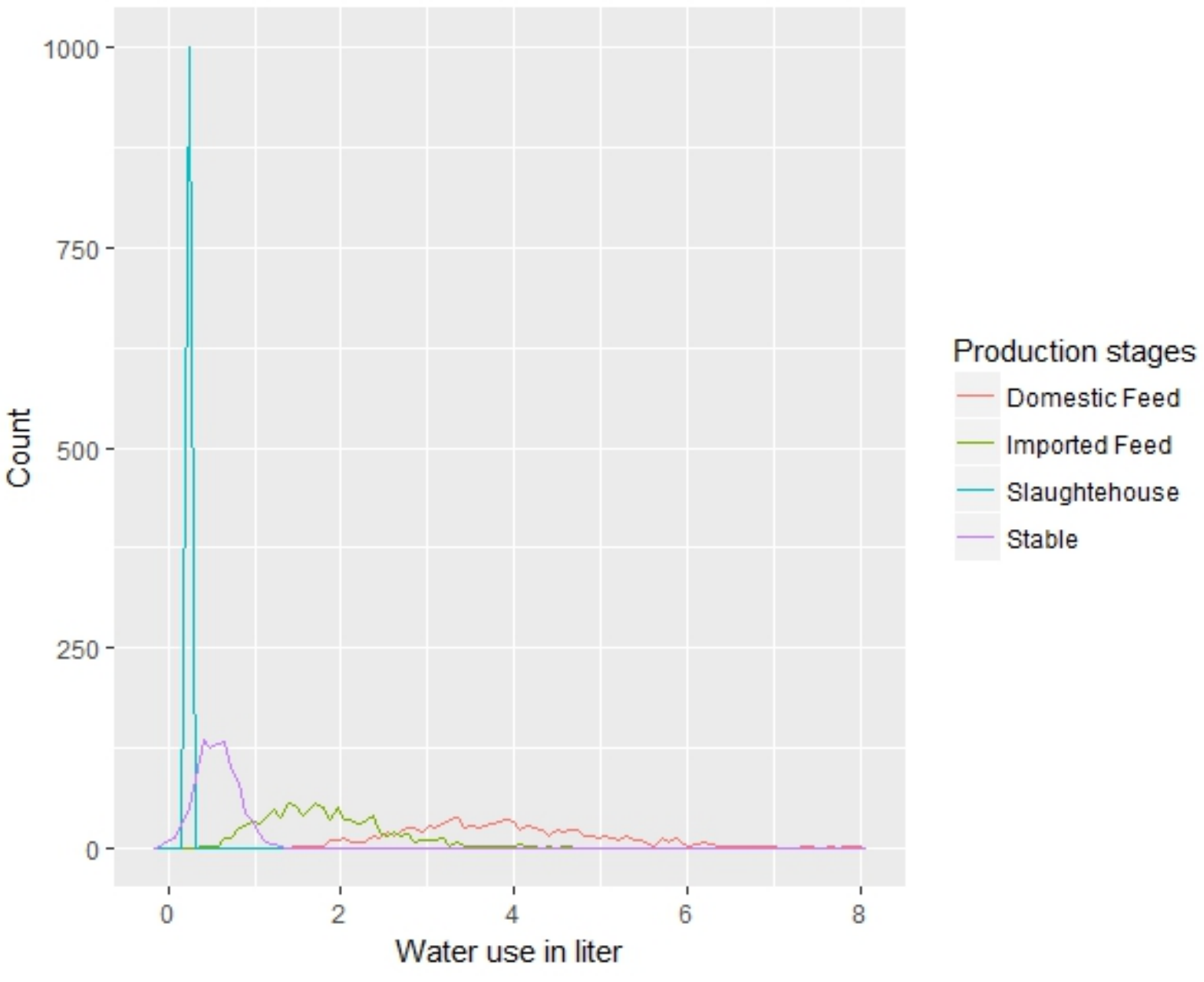

431

432 Figure 2 Probability density function of the Water Footprint Inventory (WFI) in liters per 100g of pork 433 at the slaughterhouse exit gate.

434 INSERT TABLE 8 HERE

435

436 
437 Table 8 Water Footprint Inventory results for $100 \mathrm{~g}$ pork at slaughterhouse and contribution analysis 438 of Agri-footprint, Agribalyse and the current study provided as 95\% predictions. The relative 439 contributions of the different life cycle stages are shown in parentheses.

\begin{tabular}{|c|c|c|c|c|}
\hline \multirow[b]{2}{*}{ Life cycle stage: } & \multicolumn{2}{|c|}{ 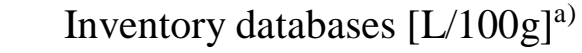 } & \multicolumn{2}{|c|}{ Current study [L/100g] $]^{\mathrm{a})}$} \\
\hline & Agri-footprint ${ }^{b)}$ & Agribalyse ${ }^{c)}$ & Best Estimate & FULL IRRI \\
\hline \multirow[t]{2}{*}{ Feed } & $1.0-1.5$ & $3.1-5.0$ & $3.0-8.3$ & $36-97$ \\
\hline & $(37-42 \%)$ & $(66-81 \%)$ & $(78-96 \%)$ & $(96-99 \%)$ \\
\hline \multirow[t]{2}{*}{ Stable } & $1.6-2.1$ & $0.7-1.6$ & $0.1-1.0$ & $0.1-1.0$ \\
\hline & $(47-51 \%)$ & $(14-28 \%)$ & $(1-17 \%)$ & $(1-3 \%)$ \\
\hline \multirow[t]{2}{*}{ Processing } & $0.38-0.42$ & $0.26-0.29$ & $0.25-0.27$ & $0.25-0.27$ \\
\hline & $(10-12 \%)$ & $(4-6 \%)$ & $(2-6 \%)$ & $(0-1 \%)$ \\
\hline Total & 3.0-3.9 & 4.4-6.6 & 3.8-9.2 & $36.8-97.8$ \\
\hline
\end{tabular}

440

441 From visual analysis of histograms and qqplots, the feed stages were generally slightly right-skewed, 442 the stables approximated a normal distribution, and the slaughterhouse was left skewed with a wide 443 hump. The slaughterhouse WFI for Agri-footprint was almost perfectly normally distributed. The total 444 water use in all four studies were approximately normally distributed (Figure 3). The F-test of equal 445 variance further rejected the hypothesis of equal variance with p-values of less than 0.001 . Thus, the 446 comparison of the distributions was carried out with the non-parametric Wilcoxon-Mann-Whitney 447 rank-sum test that yielded p-values of less than 0.001 for all comparisons. The pair-wise tests ratios 448 further supported the findings. For feed, the current study exceeded that of Agri-footprint and 449 Agribalyse in $100 \%$ and $88.4 \%$ of the simulations, respectively. For stables, the results were $0 \%$ and $4506.1 \%$, and for slaughterhouse they were $0 \%$ and $2.7 \%$ respectively. The total WFI of the Danish case 451 3.8-9.2 L/100g exceeded the WFI in Agri-footprint 3.0-3.9 L/100g in 99.1\% of the cases and 452 Agribalyse 4.4- 6.6 L/100g in $72.6 \%$ of the simulations. 


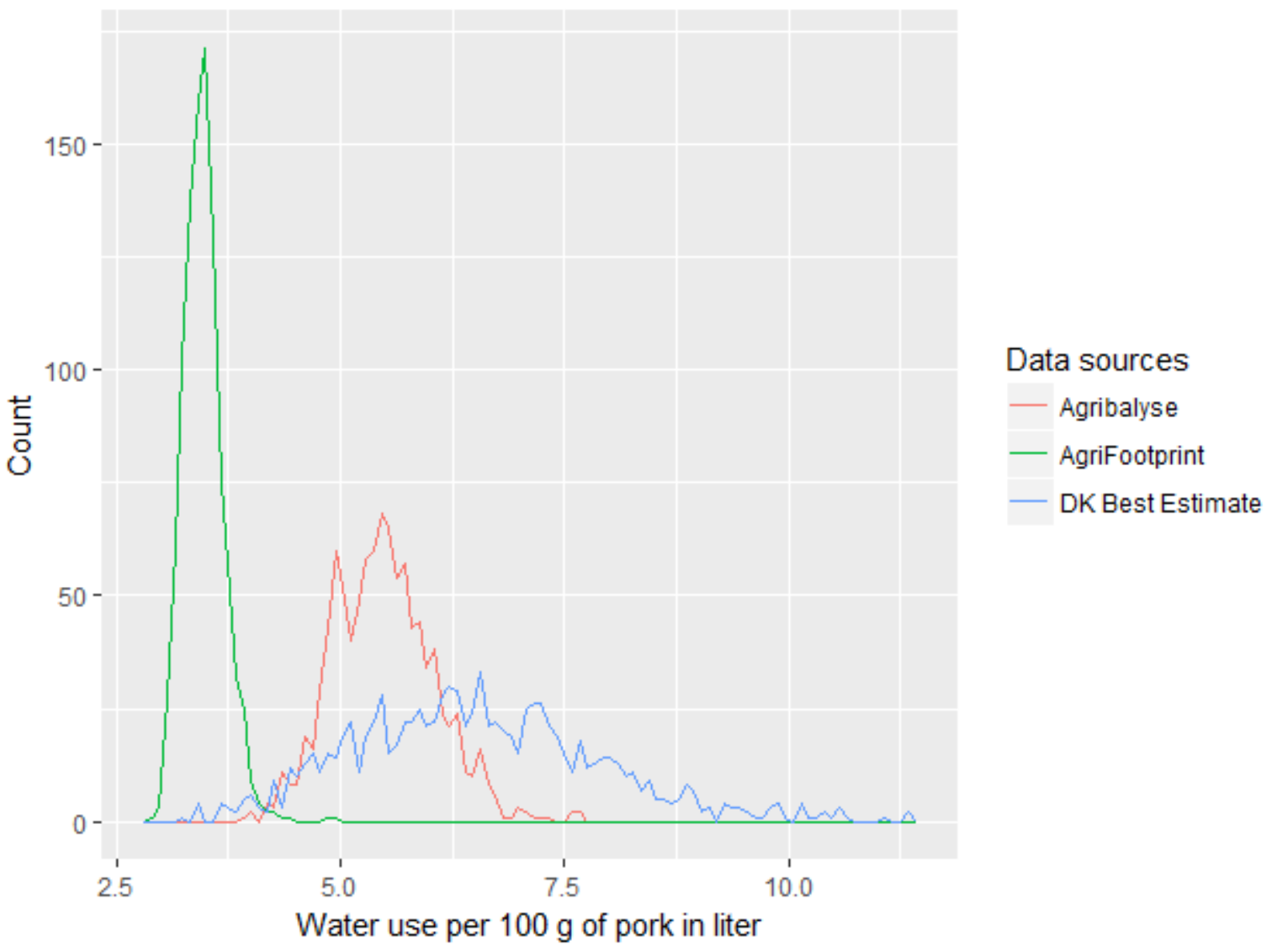

Figure 3 Probability density functions of total WFI estimates based on the best estimate of Danish pork

456

457

458

459

460

461

462

463

464

465

466

467

468

469

470 (current study), Agri-footprint and Agribalyse data, respectively.

It was found that, with 95\% confidence, WFIs for Danish pork using Agri-footprint data underestimated the water use in $\sim 99 \%$ of the studies with an effect size interval of 0.3 to $5.7 \mathrm{~L} / 100 \mathrm{~g}$. WFI estimated using Agribalyse underestimated the values in $~ 73 \%$ of studies with an effect size interval of -1.9 to $3.9 \mathrm{~L} / 100 \mathrm{~g}$. From figure 3, the lower variance of the probability density functions in the databases can be visually confirmed. The coefficient of variations increased from $6.4 \%$ and $12.3 \%$ for Agribalyse and Agri-footprint to $21 \%$ and $23 \%$ the best estimate- and the full irrigation scenario respectively.

\section{Discussion}

The blue water footprint (inventory) of Dutch pig meat reported by The Water Footprint Network (23.6 L/100g) (Mekonnen and Hoekstra, 2012) was more than two times higher than the $95^{\text {th }}$ percentile in the current study, while the WFI reported in the PEF red meat screening study (1.4 L/100g) (TS-RM, 2015), is less than half the $5^{\text {th }}$ percentile. There is hardly any overlap of the $95 \%$ prediction interval of the Agri-footprint 3.0-3.9 L/100g and the WFI in the current study 3.8-9.2 L/100g. The predicted water 
use in Agribalyse is fully captured within the prediction interval in the current study, but is still significantly left shifted. The difference between the data sources became more pronounced when evaluating the feed constituents, where prediction intervals for five out of eight crops do not overlap (Table 6). The difference in allocation of 30\% for the cereals between Agri-footprint and in the current study could not explain the witnessed discrepancies; and hence, the explanation should be found in the use of irrigation data.

The variability found in the current study was significantly higher than in all three LCI databases (Table 7). Since the first modeling in the current study was carried out, the Agri-footprint database has been updated. As a result, the variability and uncertainty of the LCIs decreased, with coefficient of variations consistently below $10 \%$. This was inconsistent with the findings in the current study and appeared counter-intuitive for agricultural production characterized by large variability. Wheat constituted the most used feed ingredient with $144 \mathrm{~g}$ of wheat per $100 \mathrm{~g}$ of pork. With wheat sourced from Denmark, it could only be said with 95\% confidence that somewhere between 0 and $\sim 490 \mathrm{~m}^{3}$ of water was used for irrigation per ton of wheat (Table 6). The current study clearly illustrated the significance of the choice of data when the WFI for wheat differed between Agri-footprint and the full irrigation scenario with $88-454 \mathrm{~m}^{3} /$ ton at the $95 \%$ confidence level.

The downstream system boundary in the PEF category rules for red meat included retail packaging and transportation to consumers (TS-RM, 2016), whereas the stages after the slaughterhouse were omitted in the current study. However, as the values in the current study were both higher and more variable than the studies and databases under comparison, there would be no need to include additional production stages to confirm the hypothesis.

The WFIs provided by Agri-footprint and Agribalyse for drinking and cleaning purposes in stables were consistent with the values in the current study. Water was modelled as released back into the same watershed, hence water use was estimated to be $0.6 \pm 0.21 \mathrm{~L} / 100 \mathrm{~g}$ of pig. Had the fate modeling been identical to Agri-footprint and Agribalyse, the mean WFI for stables would have been more or less equal, and consequently further supported the hypothesis of the study. The issue of fate modeling was equally relevant for the slaughterhouses, where the current study modeled that $91 \%$ to $99 \%$ of the water was returned to surface water. If the waste-water were discharged to sea or another catchment, the water use in processing would be almost 20 times higher, and the contribution pattern more equal to that of Agri-footprint. This would also have made the difference in assessed water use in the current study and compared the databases greater, which would have further supported the hypothesis. Assessing the effects of parameter and model choice uncertainty, such as fate modeling, would require development of fully parameterized LCI models and model-ensembling of different epistemological model representations respectively, which was beyond the scope of the project. Identifying and including more data on the water used for cleaning of pens would have enriched the picture, but would be unlikely to influence the results. 
The contribution analysis in current study revealed that more than 95\% of the water use occurred in the crop cultivation and animal rearing stages. However, these stages were considered outside the influence of the slaughterhouses and feed manufacturers in the PEF category rules for red meat (TS-RM, 2016) as well as category rules for feed products (TS-FP, 2018) and can thus be modeled with generic data and results reported as mean values, according to this guideline. While substituting primary for secondary data may not bias comparisons between slaughterhouses, it does mean that pork value chains, performing below average, can model and communicate PEF-compliant EPDs using generic data and achieve lower water footprints than if they compiled and reported specific data.

De-incentivizing primary data provision is an undesirable situation, and a first logical step to counter this could be to create data quality requirements that require modeling the life cycle stages contributing to the majority of the elementary flows with primary data. However, obtaining primary data broadly for all processes might be prohibitively costly. Another and easily implementable approach would be to make assessment and reporting of uncertainty obligatory when carrying out EPDs. This would have multiple derived benefits. When results are communicated as prediction intervals instead of descriptive values, EPDs could be tagged to any product, even when the only available information known is the product category. Products attributed with verified PEF declarations can be compared to non-declared products by saying, 'The WFI of this piece of Danish pork, with 95\% confidence lies within $3.9-9.2$ L/100g. In comparison, our product has a verified WFI of 4.1 - $4.7 \mathrm{~L} / 100 \mathrm{~g}$ '. From a legal perspective, this approach would be immune to lawsuits for injuries, as the claims are indisputable, albeit imprecise. From a modeling and statistical perspective, it is crucial to assure that prediction intervals of elementary flows include the true value. From a sustainability perspective, it is of paramount importance to avoid overshooting ecological boundaries. If the variability of the LCI databases were set to reflect the intra-product category variability, it can be argued that, from an economic perspective, attributing products with prediction intervals would incentivize companies and value chains to provide specific data. The reason would be that each additional data point narrows the prediction interval, which improves the trust in the EPD, and thereby increase the consumer's willingness to pay. Ultimately, this could create an intrinsic value of primary data.

The limitations of the study include assessment of how normative choices (such as the choice of perspective in regards to allocation, data assumptions and boundaries and cut-offs at the micro(processes) and macro level (product systems)) affected the prediction interval. The choice of only using economic allocation, and not modeling the effect of using mass- and biophysical allocation or substitution, limited the understanding of these sources of variability. The use of artificially low minima and high maxima served to capture the full width of the prediction interval of the WFI. Together with modeling all variables as independent, this could have potentially led to too-wide prediction intervals. The universal choice of triangular distribution reduced this effect compared to applying a uniform distribution, which is often the default when the distribution is unknown. Additionally, it could be argued that the true intervals could have been even greater than the prediction interval estimated because the use of pre-averaged data introduced a systematic bias with Monte Carlo 
545 simulations, and potentially omitted the tails of the distributions (McAuliffe et al., 2018). Choosing not 546 to parameterize the feed import mix further reduced the variability and could have caused a shift in the 547 contribution analysis. For instance, shifting import of soybean from Argentina to Brazil would have 548 had a significant effect on the surface and groundwater use, as irrigation data in Table 3 illustrated. To 549 fully understand the effect of each input parameter on the result, a parametrized model should be 550 complemented with a sensitivity analysis. In the future, such types of models could inform producers 551 on the key parameters to report in order to narrow the prediction intervals of their EPD.

552

553

554

555

556

557

558

559

560

561

562

563

564

565

566

567

568

569

570

571

572

573

574

575

576

577

\section{Conclusions}

The results of the current study were clear. The assessed WFI for pork and feedstuff reported in the Life Cycle Inventory (LCI) databases, applicable to Danish production, were significantly lower than the modeled WFI in the current study. Furthermore, the coefficient of variations were significantly lower in the LCI databases than in the current study. If the variance and uncertainty of the elementary flows for a product category are not properly accounted for in LCI databases, the use of generic data could provide a false sense of the robustness of the studies. Beyond the scientific shortcoming, this could compromise the validity of the assessment of the environmental sustainability of pork production. If the prediction intervals do not capture the true values and are systematically biased towards lower WFI values, there is a risk of underestimating the value chain water use.

The cultivation of feed ingredients is responsible for 78 - 99\% of the surface- and groundwater use. However, the European Commission's Product Environmental Footprint (PEF) category rules for feed do not require primary data for these production stages. In conjunction with the systematically lower water use in the recommended databases, the water use for some feed crops could be underestimated by as much as 90 times their actual values, and when these results are communicated to consumers it qualifies as greenwashing. If the PEF guidelines were to demand specific data for the feed cultivation stages, the risk of underestimating water could be reduced. Additionally, such regulatory pull for data could increase the value of environmental data.

However, obtaining primary data broadly is prohibitively expensive. As an alternative approach, it is recommended that any Environmental Product Declaration (EPD) initiative, like PEF, include quantification and reporting of uncertainty as an obligatory requirement. Together with revising the LCI databases so that the variability of the inventories reflects the variability in real life, businesses are incentivized to provide data, as each data point would narrow the prediction interval resulting in more accurate EPDs. Ultimately, this is known to enhance consumer trust and willingness to pay.

\section{Conflict of interest}

No conflict of interests has been identified. The main author is on a full and independent scholarship. 


\section{Acknowledgements}

579 We express our sincere gratitude to our colleagues at the Section for Agricultural Systems and

580 Sustainability at the Department of Agroecology at Aarhus University. In special, we would like to 581 thank Heidi Mai-Lis Andersen and Troels Kristensen for assistance with estimating water use in the 582 stables, Lisbeth Mogensen for assisting with data on irrigation and import mix, and finally Teodora 583 Dorca-Preda for assistance with the model setup. Finally, we would like to acknowledge the editor and 584 the excellent reviewers for their aid in improving the paper.

585 This research did not receive any specific grant from funding agencies in the public, commercial, or 586 not-for-profit sectors, but was coordinated and partly supported by the NitroPortugal EU Commission 587 H2020 Twinn-2015 coordination and support action. 


\section{References}

Andersen, A., 1985. Wateruse of lactating sows [Vandtildeling til søer i diegivningsperioden]. Landsudvalget for Svin og Videncenter for Svineproduktion, Den rullende Afprøvning.

Basset-Mens, C., van der Werf, H.M.G., 2005. Scenario-based environmental assessment of farming systems: the case of pig production in France. Agriculture, Ecosystems \& Environment 105(1), 127-144.

Berger, M., Finkbeiner, M., 2010. Water Footprinting: How to Address Water Use in Life Cycle Assessment? Sustainability, 2(4), 919-944; https://doi.org/10.3390/su2040919

Blonk, 2015a. Agri-footprint 2.0 - Part 1: Methodology and basic principles, Document version 2.0 ed., Gouda, Belgium.

Blonk, 2015b. Agri-footprint 2.0 - Part 2: Description of data, Document version 2.0 ed., Gouda, Belgium.

Ciroth, A., Muller, S., Weidema, B., Lesage, P., 2016. Empirically based uncertainty factors for the pedigree matrix in ecoinvent. The International Journal of Life Cycle Assessment 21(9), 13381348.

DAFC, Vils, E., 2015. Danish national average pig feed composition, in: Hermansen, J.E. (Ed.).

de Miguel, Á., Hoekstra, A.Y., García-Calvo, E., 2015. Sustainability of the water footprint of the Spanish pork industry. Ecological Indicators 57, 465-474.

DST, 2016. The Danish Statistical Online Service [Statistikbanken]. http://www.statistikbanken.dk/statbank5a/default.asp?w=1680. (Accessed 12-21 2016).

EC-JRC-IES, 2010. International Reference Life Cycle Data System (ILCD) Handbook - General guide for Life Cycle Assessment - Detailed guidance., in: Sustainability, E.C.-J.R.C.-I.f.E.a. (Ed.). Luxembourg.

EC-JRC, 2013. Product Environmental Footprint (PEF) Guide, Official Journal of the European Union. European Commission Joint Research Centre, Brussels, Belgium

EC, 2013. COMMUNICATION FROM THE COMMISSION TO THE EUROPEAN PARLIAMENT AND THE COUNCIL Building the Single Market for Green Products Facilitating better information on the environmental performance of products and organisations. Brussels.

EC, 2016. Environmental Footprint Guidance document, - Guidance for the implementation of the EU Product Environmental Footprint (PEF) during the Environmental Footprint (EF) pilot phase, version 5.2, February 2016

FAO, 2016. FAOSTAT http://www.fao.org/faostat/en/\#data. (Accessed 12-14 2016).

GEUS, 2017. Database of boreholes (in Denmark) [Boringsdatabasen]. http://data.geus.dk/geusmap/?mapname=jupiter\#zoom=5.96950169755422\&lat=6225000\&lon= 557500 \&visiblelayers=Topografisk\&filter=\&layers=\&mapname=jupiter\&filter=\&epsg=25832 \&mode=map\&map_imagetype=png\&wkt=. (Accessed 01-18 2017).

González-García, S., Belo, S., Dias, A.C., Rodrigues, J.V., Costa, R.R.d., Ferreira, A., Andrade, L.P.d., Arroja, L., 2015. Life cycle assessment of pigmeat production: Portuguese case study and proposal of improvement options. Journal of Cleaner Production 100, 126-139.

Gutiérrez, AS, Eras, JJC, Billen, P., \& Vandecasteele, C. (2016). "Environmental assessment of pig production in Cienfuegos, Cuba: alternatives for manure management, Journal of cleaner production, 112, 2518-2528, http://dx.doi.org/10.1016/j.jclepro.2015.09.082

Hansen, B., Thorling, L., Schullehner, J., Termansen, M., Dalgaard, T., 2017. Groundwater nitrate response to sustainable nitrogen management. Scientific Reports 7(1), 8566. 
Hoekstra, A.Y., 2016. A critique on the water-scarcity weighted water footprint in LCA. Ecological Indicators 66, 564-573.

Hoekstra, A.Y., Chapagain, A.K., 2007. Water footprints of nations: Water use by people as a function of their consumption pattern. Water Resources Management 21(1), 35-48.

Hoekstra, A.Y., Chapagain, A.K., Aldaya, M.M., Mekonnen, M.M., 2011. The water footprint assessment manual: Setting the global standard. Earthscan. Cornwall, United Kingdom.

Huijbregts, M.A.J., 1998. Application of uncertainty and variability in LCA. The International Journal of Life Cycle Assessment 3(5), 273.

Hvid, S.K., . 2011. Irrigation needs 1987-2010 [Markvandingsbehov 1987-2010]. Planteavlsorientering 616.

ISO14044, 2006. ISO 14044:2006 Environmental management -- Life cycle assessment -Requirements and guidelines. ISO copyright office, Geneva, Schwitzerland.

ISO14046, 2014. ISO 14046 Environmental management - Water footprint - Principles, requirements and guidelines. ISO copyright office, Geneva, Schwitzerland.

Jessen, O., 2016. Country average for productivity in pork production in 2015 [LANDSGENNEMSNIT FOR PRODUKTIVITET I SVINEPRODUKTIONEN 2015]. Videnscenter for svineproduktion, Copenhagen.

Jørgensen, L., Normander, B., Skovsbøl, U., Bech, G., Agger, P., Thorsen, T., Dubgaard, A., Boye, S., Vogdrup-Schmidt, M., Dalgaard, T., Kristensen, I., Kristensen, D., Kjeldsen, C., 2015. Scenarios for the agriculture of the future - main report [Scenarier for Fremtidens Landbrug Hovedrapport]. Det Økologiske Råd, Københavns Universitet og Aarhus Universitet, København, Denmark.

Koch, P., Salou, T., 2015. AGRIBALYSE®: Methodolopgy Report - Version 1.2 [AGRIBALYSE®: Rapport Méthodologique - Version 1.2.], in: ADEME (Ed.). Angers. France, p. 385.

Koch, P., Salou, T., 2016. AGRIBALYSE®: Methodolopgy Report - Version 1.3 [AGRIBALYSE®: Rapport Méthodologique - Version 1.3], in: ADEME (Ed.). Angers, France, p. 322.

Larsson, K., 1997. Evaluation of watering systems with bite valves for pigs, JTI-report Agriculture \& Industry. Swedish Institute of Agricultural Engineering, Uppsala, Sweden

Li, Y.Z., Chénard, L., Lemay, S.P., Gonyou, H.W., 2005. Water intake and wastage at nipple drinkers by growing-finishing pigs1. Journal of Animal Science 83(6), 1413-1422.

Madsen, H., Griensven, A.v., Højbjerg, A.L., 2010. Model calibration and validation in model-based water management, in: Vanrolleghem, P.A. (Ed.) Modelling Aspects of Water Framework Directive Implementation. IWA, London, United Kingdom, p. 260.

Magowan, E., O’Connell, N.E., McCann, M.E.E., 2007. The effect of drinker design on the performance, behaviour and water usage of growing pigs. Agri-Food and Biosciences Institute. Hillsborough, United Kingdom, p. 20.

McAuliffe, G.A., Takahashi, T., Orr, R.J., Harris, P., Lee, M.R.F., 2018. Distributions of emissions intensity for individual beef cattle reared on pasture-based production systems. Journal of Cleaner Production 171, 1672-1680.

Mekonnen, M.M., Hoekstra, A.Y., 2011. The green, blue and grey water footprint of crops and derived crop products. Hydrol. Earth Syst. Sci. 15(5), 1577-1600.

Mekonnen, M.M., Hoekstra, A.Y., 2012. A Global Assessment of the Water Footprint of Farm Animal Products. Ecosystems 15(3), 401-415.

Mogensen, L., Knudsen, M.T., Dorca-Preda, T., Nielsen, N.I., Kristensen, I.S., Kristensen, T., 2018. Sustainability parameters for conventional feed stuff for cattle [Bæredygtighedsparametre for 
konventionelle fodermidler til kvæg]. DCA - Nationalt Center for Fødevarer og Jordbrug. Aarhus, Denmark.

Mogensen, L., Knudsen, M.T., Preda, T., Nielsen, N.I., Kristensen, I.S., Kristensen, T., 2017. Sustainability parameters for conventional feed stuff for cattle - methods and table values [Miljøprofil for konventionelle fodermidler til kvæg - metode og tabelværdier], in: DCA (Ed.). Aarhus University, DRAFT.

Notarnicola, B., Sala, S., Anton, A., McLaren, S.J., Saouter, E., Sonesson, U., 2017. The role of life cycle assessment in supporting sustainable agri-food systems: A review of the challenges. Journal of Cleaner Production 140, 399-409.

Pfister, S., Bayer, P., 2014. Monthly water stress: spatially and temporally explicit consumptive water footprint of global crop production. Journal of Cleaner Production 73, 52-62.

Pfister, S., Boulay, A.-M., Berger, M., Hadjikakou, M., Motoshita, M., Hess, T., Ridoutt, B., Weinzettel, J., Scherer, L., Döll, P., Manzardo, A., Núñez, M., Verones, F., Humbert, S., Buxmann, K., Harding, K., Benini, L., Oki, T., Finkbeiner, M., Henderson, A., 2017. Understanding the LCA and ISO water footprint: A response to Hoekstra (2016) "A critique on the water-scarcity weighted water footprint in LCA”. Ecological Indicators 72, 352-359.

Phillips, P.A., Fraser, D., Thompson, B.K., 1990. The Influence Of Water Nipple Flow Rate And Position, And Room Temperature On Sow Water Intake And Spillage. Applied Engineering in Agriculture. 6(1): 75-78. (doi: 10.13031/2013.26348) @1990

Predicala, B.Z., Alvarado, A., C., Jin, Y., 2013. Alternatives for animal drinking and barn cleaning to reduce water use in swine production operations. Canadian Biosystems Engineering 56(5): 715.

Refsgaard, J.C., Stisen, S., Højberg, A.L., Olsen, M., Henriksen, H.J., Børgesen, C.D., Vejen, F., KernHansen, C., Blicher-Mathiesen, G., 2011. [Water balance in Denmark] Vandbalance i Danmark, in: GEUS (Ed.) DANMARKS OG GRØNLANDS GEOLOGISKE UNDERSØGELSE RAPPORT 2011/77. København, Denmark.

Schiavon, S., Emmans, G.C., 2000. A model to predict water intake of a pig growing in a known environment on a known diet. The British journal of nutrition 84(6), 873-883.

SEGES, 2016a. General conditions [Generelle forhold]. http://vsp.lf.dk/Viden/Stalde/Staldindretning/Slagtesvinestald/Generelle\%20forhold.aspx?full=1 . (Accessed 12-29 2016).

SEGES, 2016b. Stables [Stalde]. http://vsp.lf.dk/Viden/Stalde.aspx. (Accessed 01-02 2017).

Siebert, S., Döll, P., 2010. Quantifying blue and green virtual water contents in global crop production as well as potential production losses without irrigation. Journal of Hydrology 384(3-4), 198217.

Tavares, J.M.R., Filho, P.B., Coldebella, A., Oliveira, P.A.V., 2014. The water disappearance and manure production at commercial growing-finishing pig farms. Livestock Science 169, 146154.

Torrey, S., Toth Tamminga, E.L.M., Widowski, T.M., 2008. Effect of drinker type on water intake and waste in newly weaned piglets1. Journal of Animal Science 86(6), 1439-1445.

TS-FP, 2018. PEFCR Feed for food producing animals, Version 4.1, First public version, April 2018. Technical-Secretariat for the Feed Pilot, European Commision Joint Research Centre, Brussels, Belgium p. 149.

TS-RM, 2015. PEF Pilot Red Meat; Screening study. Technical-Secretariat for the Red Meat Pilot, European Commission Joint Research Centre, Brussels, Belgium. 
722 TS-RM, 2016. PEFCR Red Meat Version 1.4, Product Environmental Footprint Category Rules. Technical-Secretariat for the Red Meat Pilot, European Commission Joint Research Centre, Brussels, Belgium.

Wernet, G., Bauer, C., Steubing, B., Reinhard, J., Moreno-Ruiz, E., Weidema, B., 2016. The ecoinvent database version 3 (part I): overview and methodology. The International Journal of Life Cycle Assessment [online] 21(9), 1218-1230.

WWAP, 2015. The United Nations World Water Development Report 2015: Water for a Sustainable World. United Nations World Water Assessment Programme, Paris. 